\title{
Role of vitamin D in prevention of adverse maternal and perinatal outcome: a randomized controlled trial
}

\author{
Sujatha M. S., Shruthi K. R.*, Neelaharika
}

Department of Obstetrics and Gynecology, JSS Medical College and Hospital, Mysuru, Karnataka, India

Received: 24 March 2019

Accepted: 04 May 2019

*Correspondence:

Dr. Shruthi K. R.,

E-mail: drshruthikr@gmail.com

Copyright: (c) the author(s), publisher and licensee Medip Academy. This is an open-access article distributed under the terms of the Creative Commons Attribution Non-Commercial License, which permits unrestricted non-commercial use, distribution, and reproduction in any medium, provided the original work is properly cited.

\begin{abstract}
Background: Vitamin D deficiency is thought to be common among pregnant women and is associated with adverse maternal and perinatal outcome. Maternal and foetal outcome in pregnant women with standard obstetric care was compared with women with additional vitamin D supplementation.

Methods: A randomized comparative study was conducted on 100 patients attending the antenatal clinic at JSS Medical College and Hospital, Mysuru, Karnataka, India who were randomly grouped into group A (50 patients) who received standard obstetric care $(500 \mathrm{mg}$ calcium+200 IU vitamin D) and group B (50 patients) who received in addition to standard obstetric care supplementation of Vitamin D 1000 IU/day starting from 14 weeks of gestation till delivery. Vitamin D levels were assessed in both the groups with onset of labour by chemiluminescence immunoassay and obstetric and neonatal outcomes in both groups were compared.

Results: High incidence of vitamin D deficiency (96\%) in standard care group compared to vitamin D supplemented group $(\mathrm{p}=<0.0001)$ was noted. The study showed significant reduction in risk of Preeclampsia $(\mathrm{P}=0.004)$, GDM $(\mathrm{P}=0.02)$ and primary caesarean delivery $(0.008)$ in Vitamin $\mathrm{D}$ supplemented group. Significantly high birth weight in vitamin D supplemented group, an increase in 320 grams in birth weight was noted $(\mathrm{P}<0.0001)$.

Conclusions: There is a high incidence of subnormal vitamin D levels in antenatal women and is associated with maternal and neonatal adverse effects. Measuring Vitamin D levels and appropriate supplementation of higher dose of vitamin $\mathrm{D}$ is an effective strategy in prevention of adverse maternal and neonatal outcomes.
\end{abstract}

Keywords: Birth weight, Gestational diabetes mellitus, Primary caesarean delivery, Preecampsia, Vitamin D

\section{INTRODUCTION}

Vitamin D deficiency is an unrecognized pandemic common among children, adults and pregnant women throughout the world even in tropical countries. ${ }^{1-5}$ Maternal Vitamin D deficiency has been associated with numerous adverse maternal outcomes such as preeclampsia, gestational diabetes as hormonally active form of Vitamin D has a role in placental development and function, inflammation, angiogenesis, immunomodulation, insulin sensitivity. ${ }^{5}$
Vitamin D deficient mothers have adverse infant and foetal outcomes such as low birth weight, low APGAR scores, hypocalcaemia, rickets as maternal and infant vitamin D levels are highly correlated as vitamin D stores in infant starts with transplacental transfer of $25(\mathrm{OH})$ Vitamin D in early pregnancy. ${ }^{6-10}$ The research about Vitamin D related problems had resurfaced the medical world as it is a preventable health problem. Hence understanding of vitamin $\mathrm{D}$ deficiency among pregnant women and its offspring is of global health importance. 


\section{Screening for Vitamin D deficiency in pregnancy}

Current prenatal care does not include the monitoring of Vitamin D levels and no national organisation recommends routine Vitamin D screening and supplementation during pregnancy unless a women is at nutritional risk. ${ }^{11-13}$ As the test is expensive, offering it to all at risk women may not be cost effective compared to offering universal supplementation, particularly as treatment is regarded as being very safe. Women with more than one risk factor for Vitamin D deficiency which includes women with low calcium concentration, bone pain, gastrointestinal disease, alcohol abuse, a previous child with rickets and those receiving drugs which reduce Vitamin D levels should have plasma $25(\mathrm{OH})$ Vitamin D level drawn at the beginning of gestation and at mid pregnancy. ${ }^{14,15}$ Due to differences in $25(\mathrm{OH})$ D measurement techniques and variability of Vitamin D levels in the human body, there is a lack of consensus on the cut off points. The conservatively used cut off points are deficient if $<20 \mathrm{ng} / \mathrm{ml}$, insufficient if $21-30 \mathrm{ng} / \mathrm{ml}$ and optimal if $>30 \mathrm{ng} / \mathrm{ml}$.

\section{METHODS}

The study was conducted at JSS Medical college and hospital, Mysore in Department of Obstetrics and Gynaecology over a period of 23 months from November 2014 to September 2016 after getting approval from Institutional Ethical Committee (IEC). 100 antenatal women attending JSSH who registered in 1st trimester of pregnancy were included in the study and enrolled in pretested proforma and were randomized into group A and group B by computer generated randomized sampling technique after excluding chronic hypertension, overt diabetes, chronic renal disease, chronic liver disease, patients treated with anti tubercular and anti epileptic drugs within past 3 months.

Group A included pregnant women receiving standard obstetric care (SOC) $(500 \mathrm{mg}$ calcium +200IU Vitamin
D), group B included pregnant women who received in addition to standard obstetric care, vitamin D supplementation of $1000 \mathrm{IU}$ of cholecalciferol, every day starting from 14 weeks of gestation till delivery. Vitamin $\mathrm{D}$ assay were done at the onset of labour. $3 \mathrm{ml}$ of plain blood samples were collected and sent for $25(\mathrm{OH})$ vitamin $\mathrm{D}$ estimation by Chemiluminescent method using instrument Roche cobas e411 and Vitamin D Total kit. Maternal and foetal outcomes were compared in both groups.

\section{Statistical analysis}

Statistical analysis was carried out using commercial software SPSS (Statistical Package for Social Science) version 20. Descriptive statistics, t-test for independent samples, chi- square test were performed. Level of significance was expressed as $\mathrm{P}$ value $<0.05$.

\section{RESULTS}

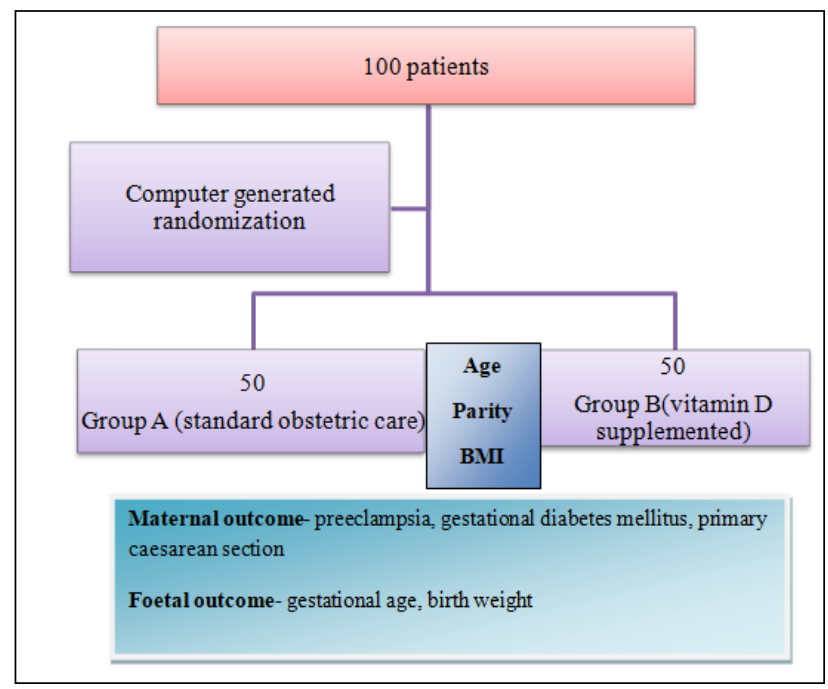

Figure 1: Diagram showing the randomization and follow-up of patients.

Table 1: Comparison of demographic parameters.

\begin{tabular}{|lllll|}
\hline \multirow{2}{*}{ Parameter } & \multicolumn{2}{l|}{ Standard Obstetric care group } & \multicolumn{2}{l|}{ Vitamin D supplemented group } \\
\hline Age $<20$ years & $\mathbf{N}$ & $\mathbf{\%}$ & $\mathbf{N}$ & $\mathbf{\%}$ \\
\hline $21-29$ years & 6 & 12 & 5 & 10 \\
\hline$>30$ years & 38 & 76 & 39 & 78 \\
\hline Mean age $($ years $)$ & 6 & 12 & 6 & 12 \\
\hline BMI- $<25 \mathrm{~kg} / \mathrm{m}^{2}$ & $25.8 \pm 3.3$ & & $25.9 \pm 3.2$ & \\
\hline $23.1-30 \mathrm{~kg} / \mathrm{m}^{2}$ & 8 & 16 & $\mathbf{7}$ & 14 \\
\hline$>30.1 \mathrm{~kg} / \mathrm{m}^{2}$ & 16 & 32 & 17 & 34 \\
\hline Mean BMI $\left(\mathrm{kg} / \mathrm{m}^{2}\right)$ & 26 & 52 & 26 & 52 \\
\hline Parity primigravida & $29.62 \pm 3.41$ & & $29.28 \pm 2.98$ & \\
\hline multigravida & 32 & 64 & 34 & 68 \\
\hline
\end{tabular}


Among the total of 100 patients, 50 patients belonging to group A who received standard obstetric care and the other 50 patients belonging to group B who received additional vitamin D of 1000IU along with standard obstetric care were followed up till delivery. There was no loss of follow up of patients in our study as shown in Figure 1. The results was analysed and compared in both the groups with respect to age, parity, BMI and were comparable in both groups as shown in Table 1 . Maternal outcome analysed in terms of preeclampsia, Gestational diabetes mellitus and primary caesarean section. Neonatal outcome was compared in terms of preterm delivery and birth weight. The significant finding noted in our study was relatively high incidence of vitamin D deficiency $(96 \%)$ in standard care group compared to vitamin D supplemented group $(\mathrm{p}=<0.0001)$ as shown in Table 2.

Table 2: Comparison of Vitamin D levels.

\begin{tabular}{|lllll|}
\hline \multirow{2}{*}{ Vitamin D levels } & \multicolumn{2}{l|}{ Standard obstetric care group } & \multicolumn{2}{c|}{ Vitamin D supplemented group } \\
\hline Vitamin D Deficient & N & $\%$ & N & $\%$ \\
\hline Vitamin D Insufficient & 48 & 96 & 0 & 0 \\
\hline Vitamin D Sufficient & 2 & 4 & 4 & 8 \\
\hline Mean Vitamin D level (IU/dl) & 0 & 0 & 46 & 92 \\
\hline
\end{tabular}

Table 3: Comparison of maternal outcome.

\begin{tabular}{|llllll|l|}
\hline \multirow{2}{*}{ Outcome } & Standard Obstetric care group & \multicolumn{2}{l|}{ Vitamin D supplemented group } & P value \\
\cline { 2 - 6 } & $\mathrm{N}$ & $\%$ & $\mathrm{~N}$ & $\%$ & 0.004 \\
\hline Preeclampsia & 17 & 34 & 5 & 10 & 0.02 \\
\hline Gestational diabetes mellitus & 11 & 22 & 3 & 6 & 0.008 \\
\hline Primary caesarean section & 9 & 18 & 1 & 2 & \\
\hline
\end{tabular}

Table 4: Comparison of neonatal outcome.

\begin{tabular}{|c|c|c|c|c|c|}
\hline \multirow[t]{2}{*}{ Outcome } & \multicolumn{2}{|c|}{ Standard obstetric care group } & \multicolumn{2}{|c|}{$\begin{array}{l}\text { Vitamin D supplemented } \\
\text { group }\end{array}$} & \multirow[t]{2}{*}{ P value } \\
\hline & $\mathbf{N}$ & $\%$ & $\mathbf{N}$ & $\%$ & \\
\hline Gestational age at delivery $<37$ weeks & 11 & 22 & 7 & 14 & \\
\hline$>37$ weeks & 39 & 78 & 43 & 86 & \\
\hline Mean gestational age (weeks) & 37.8 & & 38.88 & & 0.053 \\
\hline Birth weight $<2500$ grams & 15 & 30 & 2 & 4 & \\
\hline$>2500$ grams & 35 & 70 & 48 & 96 & \\
\hline Mean birth weight (grams) & 273 & & $3050 \pm 320$ & & 0.0001 \\
\hline
\end{tabular}

When maternal outcomes were compared in both the groups, the study showed significant reduction in risk of Preeclampsia $(\mathrm{P}=0.004)$, GDM $(\mathrm{P}=0.02)$ and primary caesarean delivery (0.008) in Vitamin D supplemented group compared to standard care group as depicted in Table 3. Mean gestational age in both groups were comparable $(\mathrm{p}=0.053)$ indicating negative correlation between gestational age of delivery and vitamin D status. One more important finding noted was significantly high birth weight in vitamin D supplemented group, compared to standard care group, an increase in 320 grams in birth weight was noted $(\mathrm{P}<0.0001)$ and the same is shown in Table 4.

\section{DISCUSSION}

During pregnancy the requirement of vitamin $\mathrm{D}$ is increased, and the synthesis, metabolism and functions of vitamin D compounds throughout gestation are different. The aim of the present study was to contrast the maternal and neonatal outcomes in the standard obstetric care subjects (group A) with the subjects who received additional 1000 IU of vitamin D daily (group B) starting from 14 weeks of gestation. The most important finding observed in the present study was significantly high incidence of vitamin D deficiency in standard obstetric care group compared to vitamin D supplemented group ( $\mathrm{P}<0.0001)$. Of the 50 patients who received standard obstetric care, 48(96\%) patients showed vitamin D deficiency with mean vitamin D level $11.82 \pm 5.83$. In contrast to this, patients who received additional Vitamin D supplementation of 1000IU/day throughout pregnancy starting from 14 weeks, 46(92\%) patients showed sufficient Vitamin D levels at the end of delivery with mean vitamin $\mathrm{D}$ levels $31 \pm 2.17$, $(\mathrm{P}<0.0001)$. In line with the present study kalra et al and Sahu $\mathrm{M}$ et al also showed 
significant increase in Vitamin D levels following supplementation. ${ }^{16,17}$ The main difference between study done by Kalra et al and our study was supplementation of single high dose, whereas in the present study same dose was supplemented in divided doses. The results in all the three studies were comparable and $25(\mathrm{OH}) \mathrm{D}$ levels were higher in Vitamin D supplemented groups in all the studies. In this study patients supplemented with 1000 IU/day Vitamin D showed reduced risk of preeclampsia by $24 \%(10 \%$ vs. $34 \%, p=0.004)$ consistent with Haugen $\mathrm{M}$ et al who also observed $27 \%$ reduction in risk of preeclampsia after vitamin D supplementation. ${ }^{18}$ Ullah et al and Bodnar LM et al also showed that vitamin D deficiency was an independent predictor of preeclampsia and patients with $25(\mathrm{OH})$ vitamin D levels $<15 \mathrm{ng} / \mathrm{mL}$ had a 5 fold increase in the risk of preeclampsia. ${ }^{19,20}$ The incidence of gestational diabetes in pregnant women who were supplemented with 1000 IU vitamin D daily was lower than the group that received 200 IU vitamin D daily ( $6 \%$ vs. $22 \%, \mathrm{P}=0.02)$. Mojibian $\mathrm{M}$ et al, also showed the incidence of GDM in supplemented group was significantly lower compared to controls (6.7\% vs. $13.4 \%, \mathrm{P}=0.01$ ) which is in comparison with the present study. $^{2}$

A positive correlation is noted between vitamin D levels and risk of nulliparous caesarean delivery. Vitamin D deficient group showed $18 \%$ risk of primary caesarean delivery compared to vitamin D sufficient group $2 \%, \mathrm{p}=$ 0.008. In line with the present study Merewood et al also found an inverse relationship between $25(\mathrm{OH}) \mathrm{D}$ levels and risk of having primary caesarean section. Women with $25(\mathrm{OH})$ vitamin D levels <37.5nmol $/ \mathrm{mL}$ almost carried fourfold higher risk of primary caesarean section22.Similar findings was observed in a study by Loy SL et al who found risk of emergency caesarean section was greater in Chinese $(\mathrm{OR}=1.90,95 \% \mathrm{CI}=$ $1.06,3.43)$ and Indian women $(\mathrm{OR}=2.41,95 \% \mathrm{CI}=$ $1.01,5.73$ ) who are vitamin $\mathrm{D}$ deficient. ${ }^{23}$ The role of Vitamin $D$ in prevention of preterm labour is controversial. Current study showed no significant effect of vitamin D supplementation on prevention of preterm birth. The mean gestational age of delivery in both the groups were comparable $(37.88 \pm 1.44$ versus $38.38 \pm 1.09$ weeks, $\mathrm{P}=0.053$ ). Similar findings were observed in a study conducted by Baker AM et al and Thorp et al. ${ }^{24,25}$ Whereas Bodnar LM et al and Thota $\mathrm{C}$ et al showed Vitamin D deficiency is associated with significant risk of preterm delivery. ${ }^{26,27}$ Several studies have reported an association between infant size and vitamin D status. Birth weight is slightly but significantly greater in the neonates of mothers who received vitamin D supplements, compared with those who did not. ${ }^{28-31}$ Our study noted 320 gms increase in birth weight in vitamin D supplemented group compared to controls (Mean birthweight: $3050 \pm 400$ vs. $2730 \pm 320$ gms, $\mathrm{P}<0.0001$ ). Scholl et al found pregnant women with vitamin D intakes $200 \mathrm{IU} / \mathrm{d}$ had infants with birth weights that were $60 \mathrm{~g}$ below women with vitamin D intakes at or above 200 $\mathrm{IU} / \mathrm{d} 32$.

\section{CONCLUSION}

- Decreased risk of preeclampsia, GDM, primary caesarean delivery in vitamin D supplemented group compared to standard care group

- Increase in birth weight by $30 \mathrm{~g}$ in Vitamin D supplemented group compared to standard obstetric care group

- High incidence of vitamin D deficiency in standard care group.

In view of the high incidence of subnormal vitamin $D$ levels in antenatal women, and increased incidence of maternal and neonatal adverse effects associated with Vitamin D deficiency, vitamin D supplements should be given to all pregnant women during their antenatal visits. The possible limitations of the present study that should be addressed and noted in future studies are unmeasured sun exposure, maternal baseline $25(\mathrm{OH}) \mathrm{D}$. Also only one blood sample during delivery was obtained, which restricts our ability to evaluate $25(\mathrm{OH})$ vitamin D concentrations in other windows. Level of calcium in studied women was an important unmeasured covariate in our study. Therefore, calcium intake may confound an association between maternal vitamin D deficiency and maternal and neonatal outcomes. The sample size of the present study was small and does not represent wide range of population. Due to limited number of interventional studies conducted in this area of interest, future RCTs should consider initiating Vitamin D supplementation early in pregnancy or even before pregnancy with good sample size that control other confounding factors will be necessary to determine a potential role for vitamin $\mathrm{D}$ in prevention of adverse maternal and neonatal outcome.

\section{ACKNOWLEDGMENTS}

Authors would like to thank his holiness Shri Shivarathreeshwara Deshikendra Swamiji and JSS Medical College for the blessings and support. Authors also thank faculty and postgraduate students of Department of Obstetrics and gynaecology and Department of biochemistry for the immense support in carrying out this study.

Funding: No funding sources

Conflict of interest: None declared

Ethical approval: The study was approved by the Institutional Ethics Committee

\section{REFERENCES}

1. Van Schoor NM, Lips P. Worldwide Vitamin D Status. Best Pract Res Clin Endocrinol Metab. 2011;25:671-80.

2. Mithal A, Wahl DA, Bonjour JP, Burckhardt P, Dawson-Hughes B, Eisman JA, et al. Global vitamin $\mathrm{D}$ status and determinants of hypovitaminosis $\mathrm{D}$. Osteoporos Int. 2009;20:1807-20. 
3. Vander Meer IM, Middelkoop BJ, Boeke AJ, Lips P. Prevalence of vitamin D deficiency among Turkish, Moroccan, Indian and sub-Sahara African populations in Europe and their countries of origin: An overview. Osteoporos Int. 2011;22:1009-21.

4. Yu CK, Sykes L, Sethi M, Teoh TG, Robinson S. Vitamin D deficiency and supplementation during pregnancy. Clin Endocrinol (Oxf). 2009;70:685-90.

5. Bodnar LM, Catov JM, Roberts JM, Simhan HN. Prepregnancy obesity predicts poor vitamin D status in mothers and their neonates. $J$ Nutr. 2007; 137:2437-42.

6. Abrams SA. In utero physiology: Role in nutrient delivery and fetal development for calcium, phosphorus, and vitamin D. Am J Clin Nutr. 2007;85:S604-7.

7. Holick MF, Biancuzzo RM, Chen TC, Klein EK, Young A, Bibuld D, et al. Is as effective as vitamin D3 in maintaining circulating concentrations of 25hydroxyvitamin D. J Clin Endocrinol Metab. 2008;93:677-81.

8. Scholl TO, Chen X. Vitamin D intake during pregnancy: Association with maternal characteristics and infant birth weight. Early Hum Dev. 2009;85:231-4.

9. McCarty CA. Sunlight exposure assessment: Can we accurately assess vitamin D exposure from sunlight questionnaires? Am J Clin Nutr. 2008;87:S1097-101.

10. Maghbooli Z, Hossein-Nezhad A, Shafaei AR, Karimi F, Madani FS, Larijani B. Vitamin D status in mothers and their newborns in Iran. BMC Pregnancy Childbirth. 2007;7:1.

11. Bhalala U, Desai M, Parekh P, Mokal R, Chheda B. Subclinical hypovitaminosis D among exclusively breastfed young infants. Indian Pediatr. 2007;44:897901.

12. Ginde AA, Sullivan AF, Mansbach JM, Camargo CA Jr. Vitamin D insufficiency in pregnant and nonpregnant women of childbearing age in the United States. Am J Obstet Gynecol. 2010;202(5):436-8.

13. Alemu E, Varnam R. Awareness of vitamin D deficiency among at-risk patients. BMC Research Notes. 2012;5(1):17.

14. Sayers A, Tilling K, Boucher BJ, Noonan K, Tobias, JH. Predicting ambient ultraviolet from routine meteorological data; its potential use as an instrumental variable for vitamin $\mathrm{D}$ status in pregnancy in a longitudinal birth cohort in the UK. Int J Epidemiol. 2009;38:1681-8.

15. Bodnar LM, Simhan HN, Powers RW, Frank MP, Cooperstein E, Roberts JM. High prevalence of vitamin D insufficiency in black and white pregnant women residing in the northern United States and their neonates. J Nutr. 2007;137:447-52.

16. Kalra P, Das V, Agarwal A, Kumar M, Ramesh V, Bhatia E, et al. Effect of vitamin D supplementation during pregnancy on neonatal mineral homeostasis and anthropometry of the new born and infant. $\mathrm{Br} \mathrm{J}$ Nutr. 2012;108:1052-8.
17. Sahu M, Das V, Aggarwal A, Rawat V, Saxena P, Bhatia V. Vitamin D replacement in pregnant women in rural north India: a pilot study. Eu J Clin Nutr. 2009;63:1157-9.

18. Meer VIM, Middelkoop BJ, Boeke AJ, Lips P. Prevalence of vitamin D deficiency among Turkish, Moroccan, Indian and sub-Sahara African populations in Europe and their countries of origin: An overview. Osteoporos Int. 2011;22:1009-21.

19. Ullah MI, Koch CA, Tamanna S, Rouf S, Shamsuddin L. Vitamin D deficiency and the risk of preeclampsia and eclampsia in Bangladesh. Horm. Metab Res. 2013;45:682-7.

20. Bodnar LM, Catov JM, Simhan HN, Holick MF, Powers RW, Roberts JM. Maternal vitamin D deficiency increases the risk of preeclampsia. J Clin Endocrinol Metab. 2007;92:3517-22.

21. Mojibian M, Soheilykhah S, Fallah Zadeh MA, Moghadam MJ. The effects of vitamin D supplementation on maternal and neonatal outcome: A randomized clinical trial: Iran $\mathrm{J}$ Reprod Med. 2015;13(11):687-96.

22. Merewood A, Mehta SD, Chen TC, Bauchner H, Holick MF. Association between vitamin D deficiency and primary cesarean section. J Clin Endocrinol Metab. 2009;94(3):940-5.

23. Loy SL, Lek N, Yap F, Soh SE, Padmapriya N, Tan $\mathrm{KH}$, et al. Association of maternal Vitamin D status with glucose tolerance and caesarean section in a multi-ethnic asian cohort: the growing up in singapore towards healthy outcomes study. PLoS ONE. 2015;10(11):e01.

24. Baker AM, Haeri S, Camargo CA, Stuebe AM, Boggess KA. A nested casecontrol study of firsttrimester maternal vitamin D status and risk for spontaneous preterm birth. Am J Perinatol. 2011;28:667-72.

25. Thorp JM, Camargo CA, McGee PL, Harper M, Klebanoff MA, Sorokin Y, et al. Vitamin D status and recurrent preterm birth: a nested case-control study in high-risk women. BJOG. 2012;119:1617.

26. Bodnar LM, Rouse DJ, Momirova V, Peaceman AM, Sciscione A, Spong CY, et al. Maternal 25hydroxyvitamin $\mathrm{D}$ and preterm birth in twin gestations. Obstet Gynecol. 2013;122:91-8.

27. Thota C, Menon R, Fortunato SJ, Brou L, Lee JE, Al-Hendy A. 1,25-Dihydroxyvitamin D deficiency is associated with preterm birth in African American and Caucasian women. Reprod Sci. 2014;21:244-50.

28. Mannion CA, Gray-Donald K, Koski KG. Association of low intake of milk and vitamin D during pregnancy with decreased birth weight. CMAJ. 2006;174:1273-7.

29. Tustin K, Gross J, Hayne H. Maternal exposure to first-trimester sunshine is associated with increased birth weight in human infants. Developmental Psychobiol. 2004;45(4):221-30.

30. Morley R, Carlin JB, Pasco JA, Wark JD, Ponsonby AL. Maternal 25-hydroxyvitamin D concentration 
and offspring birth size: effect modification by infant VDR genotype. Eur J Clin Nutr. 2009;63:802-4.

31. Leffelaar ER, Vrijkotte TGM, van Eijsden $M$. Maternal early pregnancy vitamin D status in relation to fetal and neonatal growth: results of the multiethnic Amsterdam Born Children and their Development cohort. Br J Nutri. 2010;104(01):10817.

32. Scholl TO, Chen X. Vitamin D intake during pregnancy: Association with maternal characteristics and infant birth weight. Early Him Dev. 2009;85(4):231-4.

Cite this article as: Sujatha MS, Shruthi KR, Neelaharika. Role of vitamin D in prevention of adverse maternal and perinatal outcome: a randomized controlled trial. Int J Reprod Contracept Obstet Gynecol 2019;8:2348-53. 